\title{
A Rare Clinical Presentation of Crohn's Disease
}

\section{Raiba Deshmukh $^{1}$, Avishkar Barase ${ }^{2}$, Kshitij Kirane ${ }^{3}$, Qaidzohar Kanchwala ${ }^{4}$, Rutik Gandhi ${ }^{5}$}

${ }^{1,2}$ Associate Professor in Department of General Surgery, Symbiosis Medical College for Women \& Symbiosis University Hospital and Research Centre, Pune.

${ }^{3,4,5}$ Senior Resident, Symbiosis Medical College for Women \& Symbiosis University Hospital and Research Centre, Pune.

Corresponding Author: Raiba Deshmukh

\begin{abstract}
Crohn's disease is a chronic, transmural inflammatory disease of GIT. It can involve any part of alimentary tract from mouth to anus but mostly affects small intestine and colon ${ }^{(1)}$. Early diagnosis and prompt management of this condition is required to avoid high morbidity and mortality. We present a rare clinical presentation of Crohn's disease.
\end{abstract}

Keywords: Inflammatory polyps, hemicolectomy

\section{CASE REPORT}

40 year old patient came to OPD with a complain of decreased appetite, altered bowel habits.

There was no history of abdominal pain, distension, vomiting. There were occasional episodes of loose stools but no history of blood in stool.

He was not a known case of DM, HTN, TB, Asthma.

There was no history of any previous surgery.

Patient was given conservative line of management and was advised for follow up.

After 1 week, patient came to OPD with no relief in symptoms. Patient was referred to endoscopist for colonoscopy.

His colonoscopy was done which showed numerous polyps in splenic flexure and distal transverse colon. Ulcerations were seen at splenic flexure.

Laminal narrowing was found in mid transverse region preventing further passage of scope.
The finding suggested of polyposis syndrome?, IBD reported polyposis. Biopsy was taken to confirm the diagnosis.

Biopsy report showed evidence of inflammatory polyps with no evidence of malignancy

His routine lab reports were done and surgery was planned after medicine and anesthesia fitness.

Right extended hemicolectomy with ileodescending anastomosis was planned.

After Preoperative fitness and proper bowel preparation, surgery was planned.

On the day of surgery, proper consent was taken and complications were explained to patient. Painting and drapping was done after appropriate general anesthesia was given. Midline incision was taken. All layers of abdomen were opened. Caecum, ascending colon, transverse colon, descending colon was mobilized.

Segmental colectomy was done. It is found that there were large multiple numerous inflammatory polyps from caecum extending upto splenic flexure. There were no polyps in ileum. 


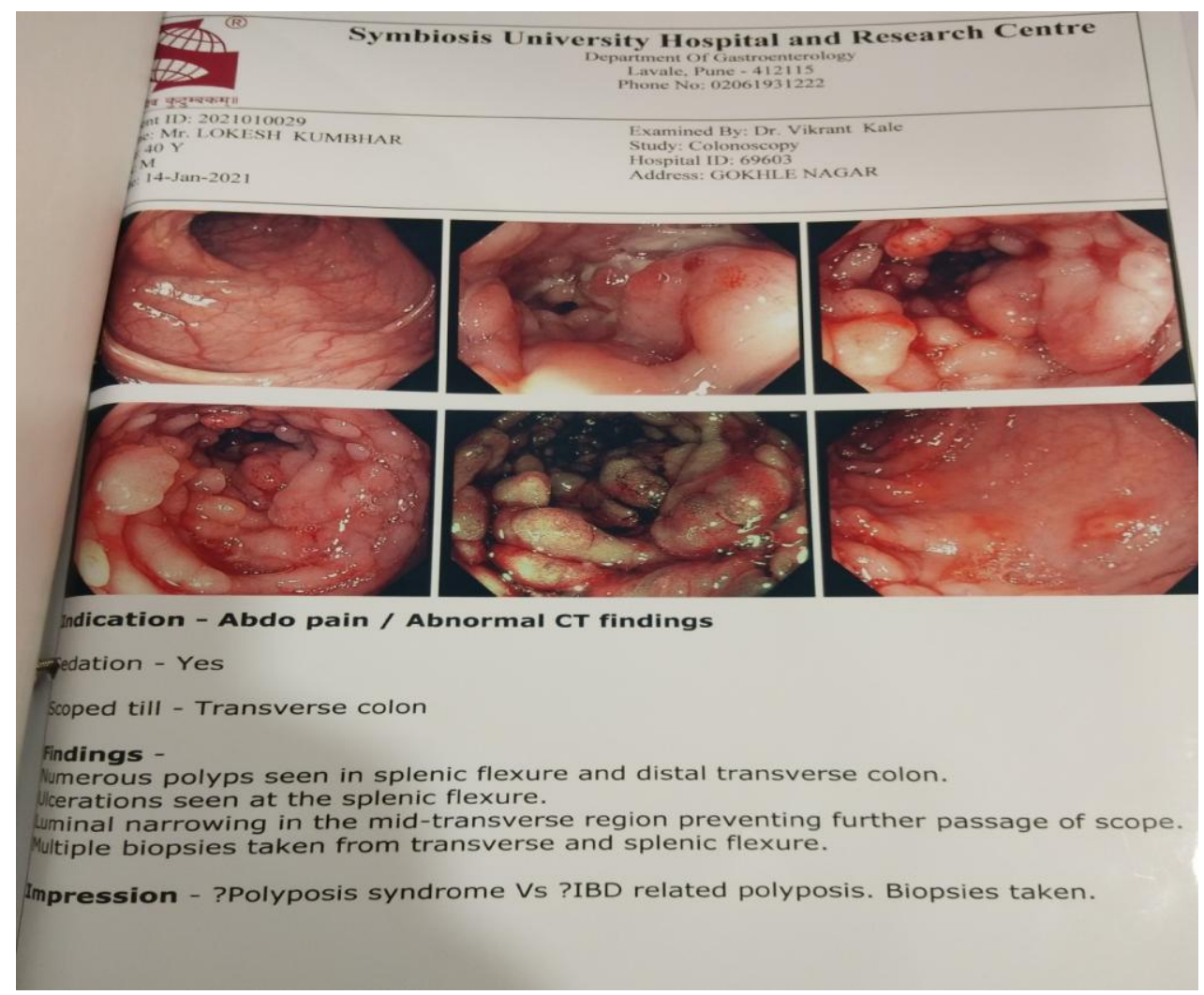

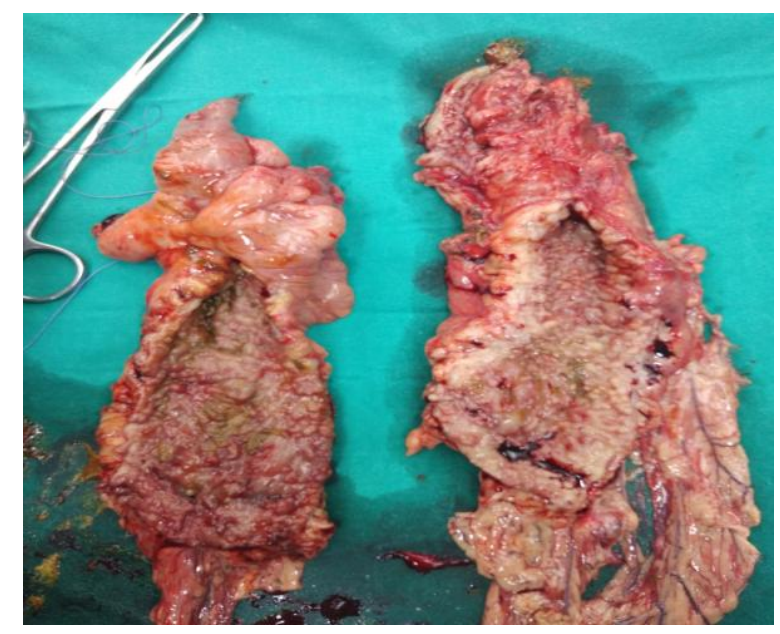

Ileodescending anastomosis was done and drain was placed in right paracolic gutter. All layers of abdomen were closed with loop ethilon and skin was sutured with 2-0 ethilon. Dressing was done.

Specimen was sent for histopathological report.

Postoperatively patient was administered with proper antibiotics, analgesia, antacids and IV fluids. Nasogastric tube aspiration was done till $5^{\text {th }}$ postoperative day and then removed.
Histopathological report was available after five day which showed evidence of Crohn's disease.

On $7^{\text {th }}$ postoperatively day drain was removed and sutures were removed on $10^{\text {th }}$ postoperatively.

Patient had no evidence of SSI and was stable. He was discharged on same day of suture removal.

\section{DISCUSSION}

Crohn's disease involves only large intestine in $15 \%$ case. Early intervention is essential to avoid complications like obstruction and perforation. ${ }^{(2)}$

Long standing Crohn's' disease predisposes to cancer of colon. ${ }^{(3)}$ Proper postoperatively management with naso gastric tube insertion is essential for healthy anastomosis.

\section{CONCLUSION}

Crohn's disease requires immediate surgical intervention without any delay followed by adequate proper postoperative care and follow-up. Diagnosis is done with clinical correlation and imaging modalities. 
Acknowledgement: None

\section{Conflict of Interest: None}

\section{Source of Funding: None}

\section{REFERENCES}

1. "Crohn's Disease". National Institute of Diabetes and Digestive and Kidney Diseases (NIDDK). Archived from the original on December 8, 2019. Retrieved December 8, 2019.

2. Carrillo, Maria (September 1, 1985). "Man of Many Problems Comes to City for
Help". Richmond Times-Dispatch.

Richmond, Virginia, USA. p. B1.

3. Ekbom A, Helmick C, Zack M, Adami HO (August 1990). "Increased risk of largebowel cancer in Crohn's disease with colonic involvement". Lancet. 336 (8711): 357-9.

How to cite this article: Deshmukh R, Barase A, Kirane $\mathrm{K}$ et.al. A rare clinical presentation of Crohn's disease. Int J Health Sci Res. 2021; 11(5): 226-228. DOI: https://doi.org/10.52403/ ijhsr.20210536 